\title{
A Monte Carlo Simulation of Pitting Corrosion of Magnesium Alloys
}

\author{
Chia-Jung Chang ${ }^{1 *}$, Tin-Kan Hung ${ }^{2}$, Wei-Ching Hung ${ }^{1}$ and Chih-Han Chang ${ }^{1}$ \\ ${ }^{1}$ Department of Biomedical Engineering, National Cheng Kung University, Taiwan \\ ${ }^{2}$ Bioengineering Department, University of Pittsburgh, USA
}

Received: 阱January 30, 2018; Published: 眥 February 05, 2018

*Corresponding author: Chia-Jung Chang, Department of Biomedical Engineering, National Cheng Kung University, Taiwan

\begin{abstract}
In recent years, many studies on magnesium (Mg) alloys are focused on developing biodegradable medical implant. Interests are also placed upon the implant geometry related to corrosion processes. In this study, a simulation model to analyze pitting corrosion of Mg alloys is established with a Monte Carlo procedure. The Mg specimen is meshed with uniform hexahedral micro elements. Each element can be characterized by a corrosion probability (CP) for a time interval. The CP value is based on factors such as the number of surfaces exposed to the solution, properties of oxide layer, the porous structure and the Mg matrix. The results are compared with experimental measurement using a micro computed tomography (CT). The computational model appears to be useful for long-term simulation and analysis of corrosion behaviors and prediction for biodegradable implant development.
\end{abstract}

Keywords: Magnesium Alloy; Micro-CT; Monte Carlo Method; Pitting Corrosion simulation

Abbreviations: Mg: Magnesium; $\mathrm{CP}_{\mathrm{i}}$ : Corrosion Probability; $\mathrm{EA}_{\mathrm{i}}$ : Expose Attribute; $\mathrm{OA}_{\mathrm{i}}$ : Oxide Attribute; $\mathrm{CA}_{\mathrm{i}}$ : Corrosion Attribute; Micro-CT : Micro Computed Tomography

\section{Introduction}

Biodegradable magnesium (Mg) alloys were investigated in recent years by many investigators for developing medical device. One of the tasks is to match corrosion rate with tissue regeneration which is a long term growth. The present study is to develop a computational procedure simulating corrosion processes. The Mgspecimen is modeled as hexahedral elements of 125 microns in size. Each element is in contact with adjacent elements or saline. The corrosion probability $\left(\mathrm{CP}_{\mathrm{i}}\right)$ for an element is determined at each time step. In this study, CPi was considered with two factors: the expose attribute $\left(E A_{i}\right)$ and oxide attribute $\left(\mathrm{OA}_{\mathrm{i}}\right)$. The number of element surfaces in contact with saline is indicated by $E A_{i}$. As the oxide magnesium surface is much slower in corrosion than the intact magnesium, the material characteristics are represented by $\mathrm{OA}_{\mathrm{i}}$. The combined effect is expressed as the corrosion attribute indicated by $\mathrm{CA}_{\mathrm{i}}=\mathrm{EA}_{\mathrm{i}}^{*} \mathrm{OA}_{\mathrm{i}}$. In the computational analysis, the corrosion rate is based on experimental data of magnesium mass loss obtained by a micro-CT every 25 hours for a period of $500 \mathrm{hrs}$. The corrosion probability of an element is

$$
\mathrm{CP}_{\mathrm{i}}=\frac{\boldsymbol{M L}}{\boldsymbol{M}_{\boldsymbol{e}}} * \frac{\boldsymbol{C A _ { i }}}{\sum_{i=1}^{\boldsymbol{n}} \boldsymbol{C A _ { i }}}
$$

In which MLis mass loss of specimen, $\mathrm{M}_{\mathrm{e}}$ the mass per element, and $\sum_{\boldsymbol{i}=\mathbf{1}}^{\boldsymbol{n}} \boldsymbol{C} \boldsymbol{A}_{\boldsymbol{i}}$ the total corrosion attribute of all the elements. The inhomogeneous property on the oxide layer could lead to pit corrosion [1,2]. Initially, the Mg specimen surface was a protective oxide layer. When the porous reign of oxide layer was corroded by saline, the Mg alloys matrix inside became exposed and its corrosion rate was much faster than oxide layer, resulting in pitting corrosion. In this study, the setting of three OA values were based on the corrosion rate calculated from the data of electrochemical corrosion tests [3-6] by classic Tafel analysis [7]. The Monte Carlo procedure was applied to determine which elements to be corroded in a time step.

Figure 1 shows the overall comparison of the corrosion simulation and experiment at different time: $50 \mathrm{~h}, 100 \mathrm{~h}$ and $250 \mathrm{~h}$. While the mass loss rate of the simulation is based on the 
experimental data, the corrosion patterns are related to the characteristic micro-structure of oxide layer. Figure 2 compares a corrosion simulation of the specimen surface with two inner sections at $0.125 \mathrm{~mm}$ apart. Similar patterns on these three layers show the development of pitting corrosion from surface to the mid-section, and from corrosion time of $100 \mathrm{~h}$ to $300 \mathrm{~h}$ and 500 h. Because the in homogeneity of oxide top and bottom surfaces are not the same, pitting patterns on the lower half specimen are somewhat different.

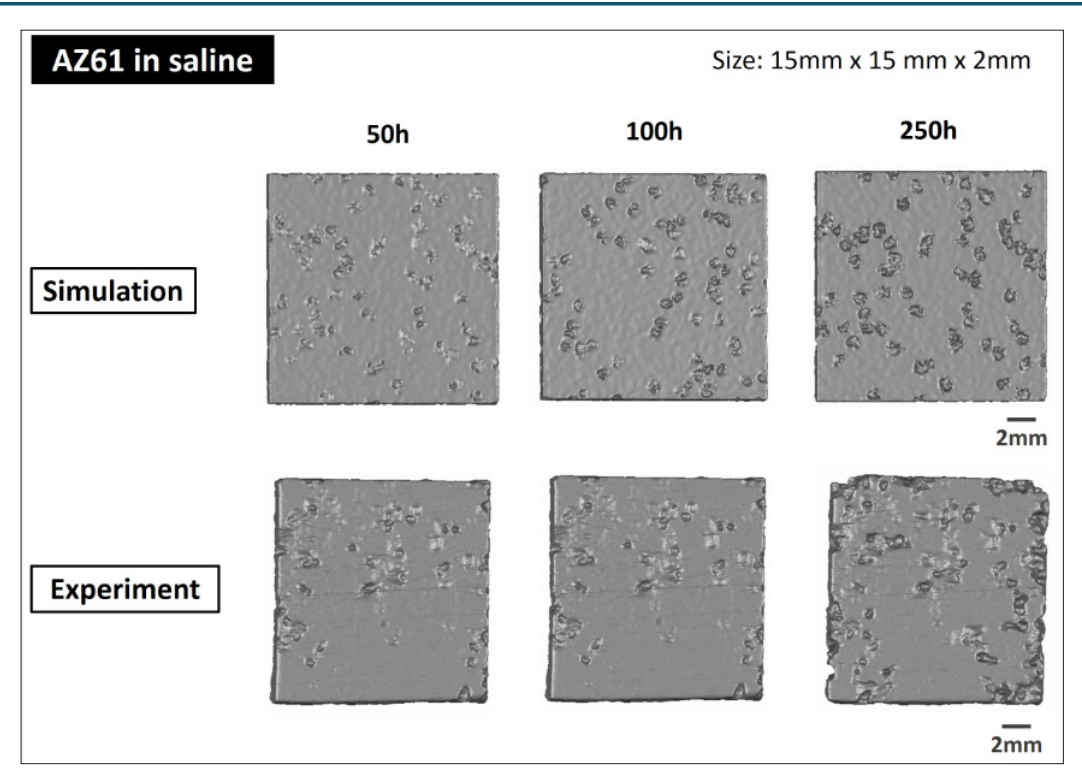

Figure 1: Overall comparison of the corrosion simulation and experiment.

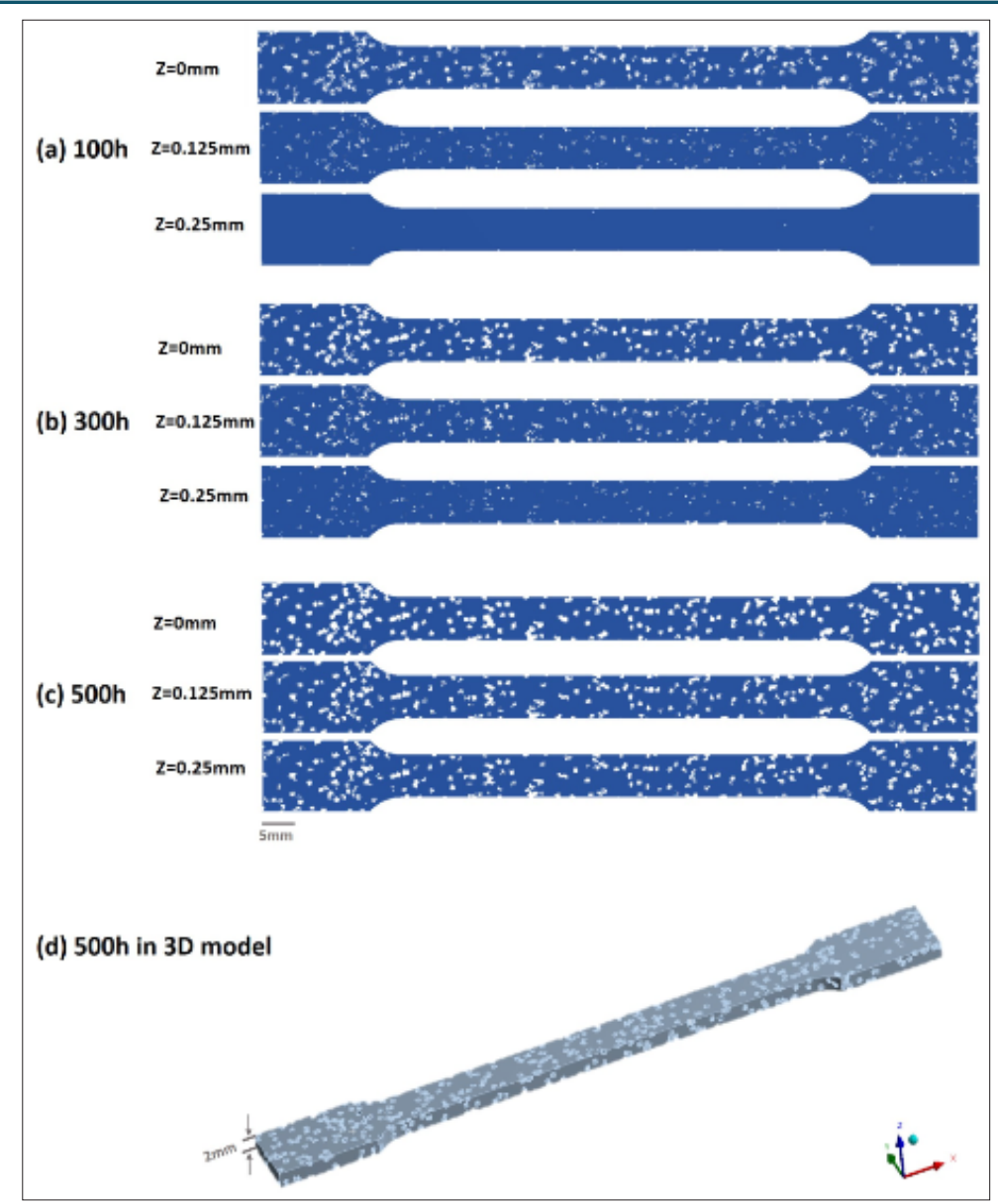

Figure 2: Corrosion simulation of a magnesium alloy; $\mathrm{z}=0 \mathrm{~mm}$ for the surface and $\mathrm{z}=0.25 \mathrm{~mm}$. 


\section{Conclusion}

The characteristic micro-structure of oxide layer is a dominant factor for corrosion simulation. The quantification of 3D images by micro-CT is useful for comparing experimental results with the simulation. The computational model for the corrosion of magnesium alloy showed a good agreement with experimental results of 500 hours. The computational model appears to be useful for long-term simulation and analysis of corrosion behaviors and prediction for biodegradable implant development.

\section{Acknowledgement}

The study is supported by the Department of Biomedical Engineering of the National Cheng Kung University. The fellowship of the Medical Device Innovation Centre for CJC to visit the University of Pittsburgh is acknowledged along with the micro-CT of the Instrument Development Centre, NCKU.

\section{References}

1. Song GL, A Atrens (1999) Corrosion mechanisms of magnesium alloys. Advanced engineering materials 1(1): 11-33.
2. Bian, L W X Z (2005) Magnesium and magnesium alloy: Central South University Press.

3. Narayanan TS, IS Park MH Lee (2015) Surface Modification of Magnesium and Its Alloys for Biomedical Applications: Modification and Coating Techniques, Elsevier.

4. Wu F, J Liang, W Li (2015) Electrochemical deposition of Mg (OH) 2/GO composite films for corrosion protection of magnesium alloys. Journal of Magnesium and Alloys 3(3): 231-236.

5. Tkacz J (2016) Corrosion behavior of wrought magnesium alloys AZ31 and AZ61 in Hank's solution. Koroze a ochrana materialu 60(4): 101106.

6. Cheng Yl (2009) Comparison of corrosion behaviors of AZ31, AZ91, AM60 and ZK60 magnesium alloys. Transactions of Nonferrous Metals Society of China 19(3): 517-524.

7. Instruments G (2011) Getting Started with Electrochemical Corrosion Measurement.

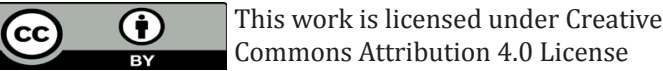

To Submit Your Article Click Here: Submit Article

DOI: 10.32474/OAJBEB.2018.01.000103

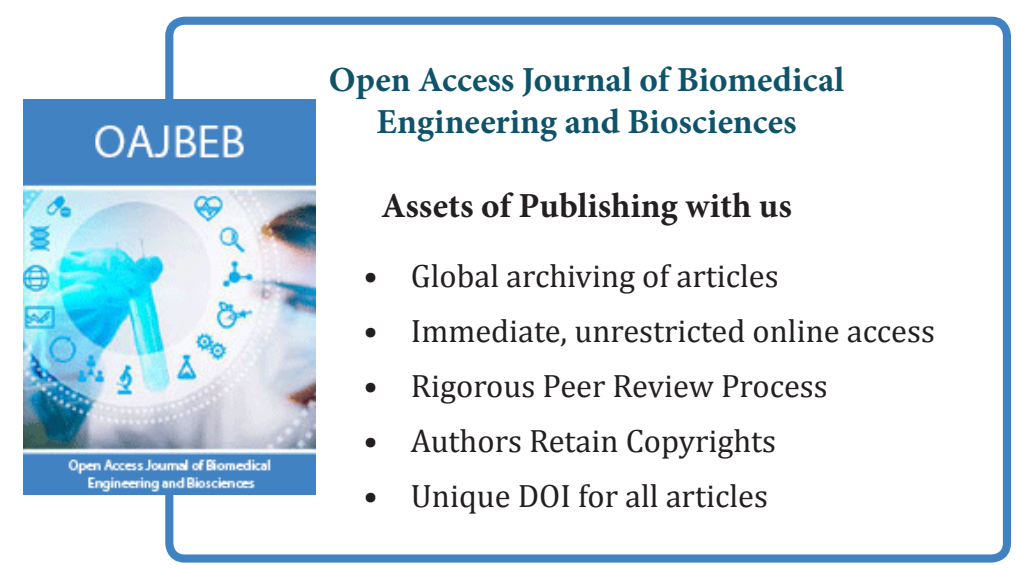

